\title{
Permanent Magnet Synchronous Motor Vector Control Based on Weighted Integral Gain of Sliding Mode Variable Structure
}

\author{
Zhang $\mathrm{Yi}^{1,2, *}$, Chen Wenjie ${ }^{2}$ and Wei Haifeng ${ }^{2}$ \\ ${ }^{I}$ School of Electrical and Information, Jiangsu University of Science and Technology, Zhenjiang, Jiangsu Province, \\ 212003, China \\ ${ }^{2}$ Jiangsu Provincial Key Laboratory of Pulp and Paper Science and Technology, Nanjing Forestry University, Nanjing, \\ Jiangsu Province, 210037, China
}

\begin{abstract}
Aiming at the slow dynamic response and the chattering problem from conventional exponential reaching law sliding mode applied in permanent magnet synchronous motor vector control in current loop, firstly this paper used weighted integral type sliding mode control algorithm to design the current loop controller. For the second step, the stability of the system was proved with lyapunov stability theory. Simulation results show that current controller of vector control system based on weighted integral gain sliding mode has strong robustness to parameter perturbation and external disturbance compared with traditional sliding mode control, and improves system's dynamic response and control precision.
\end{abstract}

Keywords: Current control, permanent magnet synchronous motor, sliding mode variable structure, vector control, weighted integral gain.

\section{INTRODUCTION}

Permanent magnet synchronous motor (PMSM) has the advantages of high efficiency, high power density and high torque/inertia ratio, which has been widely used in high performance transmission system [1]. Vector control is a high performance control strategy, and its control objective is to make the $\mathrm{AC}$ motor performance as independent excitation DC motor. Among the permanent magnet synchronous motor vector control strategy, $i_{d}=0$ control strategy is widely used for its simple structure, goodness to keep the linkage of permanent magnet synchronous motor and robustness to the motor parameter [2]. But PMSM is also a multi variable, strong coupling and non autonomous system, especially existing the coupling relationship of mechanical angular speed and armature current, which seriously affected the precise control of motor speed and can not meet the standard of system's dynamic response and control precision [3, 4]. To solve this problem, variable structure control, compound control, and the Bang-Bang control are used in current control of PMSM in order to improve the system's performance. However, fuzzy control, and the Bang-Bang control are under theoretical research with little appliance in practical engineering [5].

Variable structure control has the advantages of simple structure, the strong robustness to external disturbance and parameter perturbation, and has been widely used in motor control [6-9]. However, traditional exponential reaching law sliding mode control exists high frequency chattering phenomenon [10-13]. To solve this problem, this paper put forward the weighted integral gain of sliding mode variable structure control, whose main idea is to weaken the chattering phenomenon through reducing switching phase gain when the control system is deviated from the sliding mode dynamic [14]. This paper designs the current controller based on weighted integral gain sliding mode variable structure control for permanent magnet synchronous motor. Simulation results show that current controller of vector control system based on weighted integral gain sliding mode variable structure control has strong robustness to parameter perturbation and external disturbance compared with traditional sliding mode control, and improves system's dynamic response and control precision [15].

\section{MATHEMATICAL MODEL OF PERMANENT MAGNET SYNCHRONOUS MOTOR}

Stator of permanent magnet synchronous motor has three-phase AC windings and its rotor has permanent magnet excitation. We can neglect some secondary factors in order to facilitate the analysis, the following assumptions are made: Rotor magnetic field in air gap space and the induced electromotive force in stator armature distribute as a sine wave; ignoring the stator core saturation, the core loss and hysteresis loss; regarding the magnetic circuit linear and the inductance parameters unchangeable; neglecting damping winding on the rotor.

Based on the assumptions above, we obtain mathematical model in $d-q$ rotating coordinate through the coordinate 
transformation formula and the mathematical model of permanent magnet synchronous motor in the $A-B-C$ coordinate system. For non-salient pole permanent magnet synchronous motor existing $L_{d}=L_{q}=L$.

Therefore the voltage equation based on $d-q$ coordinate can be expressed as shown below:

$u_{d}=r i_{d}-w L i_{q}+\frac{d \psi_{d}}{d t}$

$u_{q}=r i_{q}-w L i_{d}+\frac{d \psi_{q}}{d t}$

where $u_{d}$ is the stator voltage in $\operatorname{direct}(\mathrm{d})$ axis, $u_{q}$ the stator voltage in quadrature (q) axis, $i_{d}$ the stator current in d-axis, $i_{q}$ the stator current in q-axis, $\mathrm{r}$ the stator resistance, $\omega$ the rotor mechanical angular velocity, $L$ the stator inductance.

$\psi_{d}, \psi_{q}$ are components of stator flux vector in $d-q$ coordinates:

$\psi_{d}=L i_{d}+\psi_{f}$

$\psi_{q}=L i_{q}$

where $\psi_{f}$ is the permanent magnetic flux.

The expression of electromagnetic torque for scalar form in $d-q$ coordinate:

$T_{e}=\frac{3}{2} P \Psi_{f} \mathrm{i}_{q}$

and the kinetic equations of the motor:

$T_{e}-T_{L}=\frac{J}{P} \frac{d w}{d t}$

where $T_{L}$ is the load torque, $\mathrm{P}$ the number of pole pairs, $J$ the moment of inertia, $B$ the viscous friction coefficient.

\section{WEIGHTED INTEGRAL GAIN OF SLIDING MODE VARIABLE STRUCTURE CONTROL}

\subsection{Conventional Exponential Reaching Sliding Mode Control}

Sliding mode variable structure control is essentially a kind of special nonlinear control strategy, which changes the system structure through constantly switching control quantity based on judging the switching function symbols, in order to make state variation toward the surface on the state space. For the factors, such as time delay and space lag from switching, error from state detection, which make system produce the chattering phenomenon that is harmful to motor system.
Take exponential reaching law sliding mode as follows:

$s=-\varepsilon \operatorname{sign}(\mathrm{s})-k \mathrm{~s} \quad \varepsilon>0, k>0$

Assume $s>0$, the formula (5) becomes

$s=-\varepsilon-k \mathrm{~S}$

Answer the differential equation, we get:

$s(\mathrm{t})=-\frac{\varepsilon}{k}+\left(\mathrm{s}_{0}+\frac{\varepsilon}{k}\right) \mathrm{e}^{-k t}, s_{0}=s(0)$

Seeing from the exponential reaching law, control system is operating on the sliding mode surface $s(\mathrm{t})=0$ while time is infinite

$$
\begin{aligned}
& \frac{\varepsilon}{k}=\left(\mathrm{s}_{0}+\frac{\varepsilon}{k}\right) \mathrm{e}^{-k t} \\
& \operatorname{In} \frac{\varepsilon}{k}-\operatorname{In}\left(\mathrm{s}_{0}+\frac{\varepsilon}{k}\right)=-k
\end{aligned}
$$

Solve the equation above, we get:

$t^{*}=\frac{1}{k}\left[\ln \left(\mathrm{s}_{0}+\frac{\varepsilon}{k}\right)-\ln \frac{\varepsilon}{k}\right]$

State variation reaches the switching surface in the limited time. Conventional exponential reaching law consists of two components: one is exponential reaching component $\dot{s}=-k s$, the other is constant reaching component $s=-\varepsilon \operatorname{sign}(\mathrm{s})$. If increasing the constant $\varepsilon$, normal movement phase will speed up while the chattering strengthens; if decreasing the constant $\varepsilon$, normal movement phase will slow while the chattering weakens, based on that, we get that chattering and response is a pair of contradiction. Conventional exponential reaching law sliding mode determines the constant through not only ensuring normal speed but also weakening the chattering of sliding mode phase, which can not solve the contradiction effectively.

\subsection{Design of Current Controller Based on Weighted Integral Gain Sliding Mode}

Combining (1) (2), we get mathematical model of PMSM :

$$
\begin{aligned}
& \dot{i_{d}}=-\frac{r}{L} i_{d}+w i_{q}+\frac{u_{d}}{L} \\
& \dot{i_{q}}=-\frac{r}{L} i_{q}-w\left(i_{d}+\frac{\Psi_{f}}{L}\right)+\frac{u_{q}}{L}
\end{aligned}
$$

In accordance with the sliding mode controller design, switching function is expressed as follows:

$s=\left\{\begin{array}{l}s_{1}=i_{d}{ }^{*}-i_{d} \\ s_{2}=i_{q}{ }^{*}-i_{q}\end{array}\right.$ 


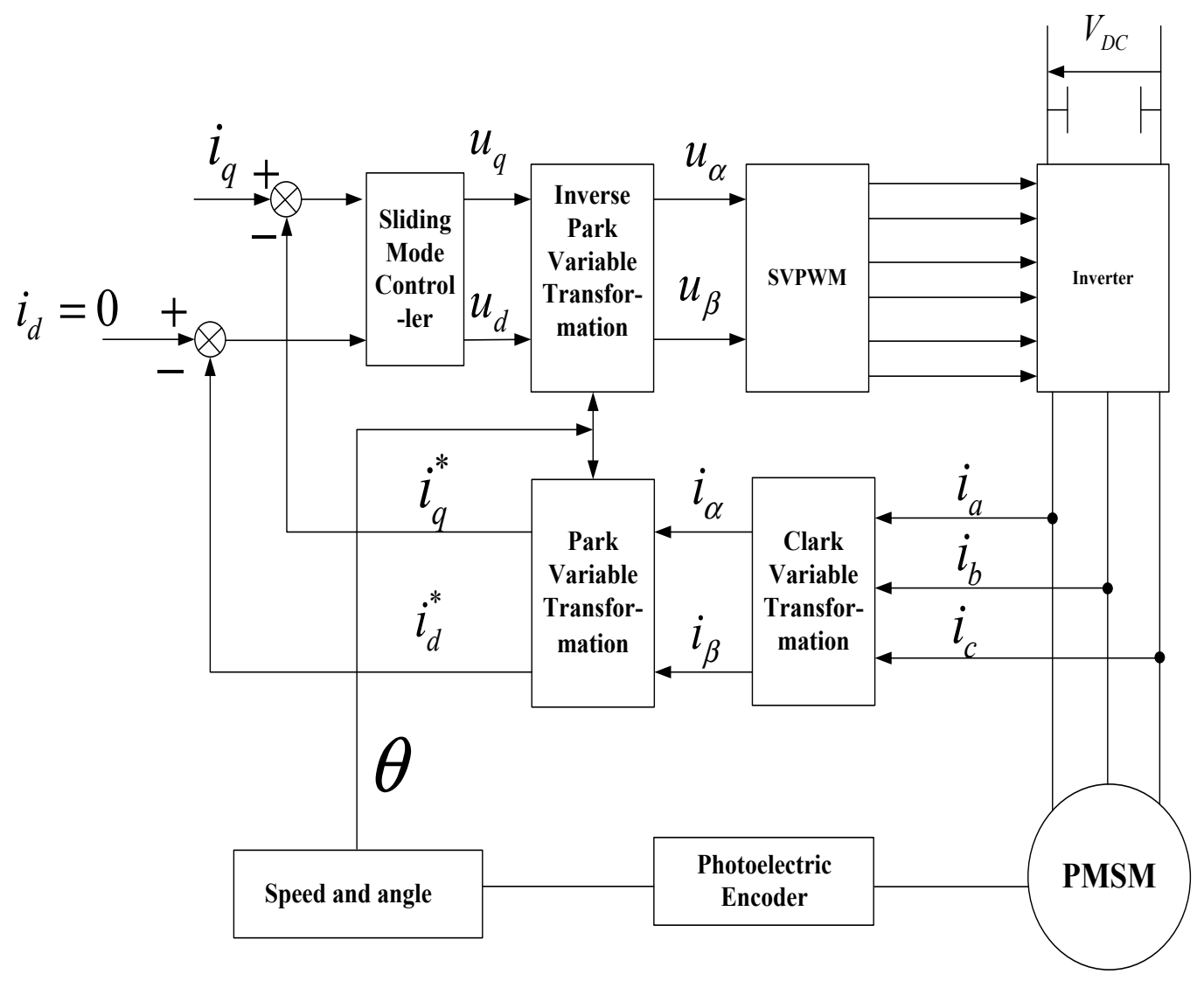

Fig. (1). Mode of permanent magnet synchronous motor vector control.

Where $i_{d}{ }^{*} 、 i_{q}{ }^{*}$ are given current value in $d-q$ rotating coordinate. Considering the change rate of the given current value $i_{d}{ }^{*} 、 i_{q}^{*}$ is slower than $i_{d}, i_{q}$.

Do derivative to variables $s_{1}$ and $s_{2}$, we get:

$$
\dot{s}=\left\{\begin{array}{l}
\dot{s_{1}}=-\left(\dot{i_{d}}\right) \\
\dot{s_{2}}=-\left(\dot{i_{q}}\right)
\end{array}\right.
$$

Substitute (10) into (12), we get:

$\dot{s_{1}}=\frac{r}{L} i_{d}-w i_{q}-\frac{u_{d}}{L}$

$\dot{s_{2}}=\frac{r}{L} i_{q}+w\left(i_{d}+\frac{\Psi_{f}}{L}\right)-\frac{u_{q}}{L}$

Arrange (13) into the matrix $\dot{S}=F+D U$, the matrix parameters are expressed as follows:

$$
F=\left[\begin{array}{ll}
F_{1} & F_{2}
\end{array}\right]^{T}=\left\{\begin{array}{l}
\frac{r}{L} i_{d}-w i_{q} \\
\frac{r}{L} i_{q}+w\left(i_{d}+\frac{\Psi_{f}}{L}\right)
\end{array}\right.
$$

$$
D=-\frac{1}{L}\left[\begin{array}{ll}
1 & 0 \\
0 & 1
\end{array}\right], \quad U=\left[\begin{array}{ll}
u_{d} & u_{q}
\end{array}\right], \quad \text { take Lyapunov }
$$

function $V=S^{T} S / 2$ and do derivative to it, we get:

$$
\dot{V}=S^{T} \dot{S}=S^{T}(\mathrm{~F}+D U)
$$

In order to ensure $\dot{V}<0$, guarantee the sliding mode control system to own good dynamic quality in normal motion stage and weaken the chattering from conventional exponential reaching law sliding mode, we select the weighted integral gain sliding mode variable structure control to design current controller, control law is expressed as follows:

$U=-D^{-1}\left[\begin{array}{c}F_{1}+K_{1} s_{1}+K_{2} \int_{0}^{t_{1}}\left|\mathrm{~s}_{1}+\rho_{1} s_{1}^{\alpha_{1} / \beta_{1}}\right| d t \cdot \operatorname{Sign}\left(\mathrm{s}_{1}\right) \\ F_{2}+K_{3} s_{2}+K_{4} \int_{0}^{t_{2}}\left|\mathrm{~s}_{2}+\rho_{2} s_{2}^{\alpha_{2} / \beta_{2}}\right| d t \cdot \operatorname{Sign}\left(\mathrm{s}_{2}\right)\end{array}\right]$

Where $K_{1} 、 K_{2} 、 K_{3} 、 K_{4}$ are positive constants, $\alpha_{1}$ 、 $\alpha_{2} 、 \beta_{1} 、 \beta_{2}$ positive odds, $-1<\rho_{1}<0,-1<\rho_{2}<0$.

Substitute (16) into (15), we get:

$$
\begin{aligned}
& \dot{V}=-s_{1}\left(K_{1} s_{1}+K_{2} \int_{0}^{t_{1}}\left|\mathrm{~s}_{1}+\rho_{1} s_{1} \alpha_{1} / \beta_{1}\right| d t \cdot \operatorname{Sign}\left(\mathrm{s}_{1}\right)\right)- \\
& s_{2}\left(K_{3} s_{2}+K_{4} \int_{0}^{t_{2}}\left|\mathrm{~s}_{2}+\rho_{2} s_{2}^{\alpha_{2} / \beta_{2}}\right| d t \cdot \operatorname{Sign}\left(\mathrm{s}_{2}\right)\right)<0
\end{aligned}
$$


Because $s_{1}$ and $\left(K_{1} s_{1}+K_{2} \int_{0}^{t_{1}}\left|\mathrm{~s}_{1}+\rho_{1} s_{1}^{\alpha_{1} / \beta_{1}}\right| d t \cdot \operatorname{Sign}\left(\mathrm{s}_{1}\right)\right)$ are same symbol, $s_{2}$ and $\left(K_{3} s_{2}+K_{4} \int_{0}^{t_{2}}\left|\mathrm{~s}_{2}+\rho_{2} s_{2}{ }^{\alpha_{2} / \beta_{2}}\right| d t \cdot \operatorname{Sign}\left(\mathrm{s}_{2}\right)\right)$ are as well, we can select $K_{1} 、 K_{2} 、 K_{3} 、 K_{4}$ to be positive constants to ensure $\dot{V}>0$, and finally control system can realize the sliding mode motion through ensuring the existence and accessibility. When the system state variations are on the switching surface through satisfying $s_{1}=i_{d}{ }^{*}-i_{d}=0$ and $s_{2}=i_{q}{ }^{*}-i_{q}=0$, so that it is easy to guarantee practical current $i_{d} 、 i_{q}$ in $d-q$ rotating coordinate track the rated current $i_{d}{ }^{*} 、 i_{q}{ }^{*}$.

Substitute $U$ into (15), we get

$$
\dot{S}=F+D U=\left\{\begin{array}{l}
-\left(K_{1} s_{1}+K_{2} \int_{0}^{t_{1}}\left|\mathrm{~s}_{1}+\rho_{1} s_{1}^{\alpha_{1} / \beta_{1}}\right| d t \cdot \operatorname{Sign}\left(\mathrm{s}_{1}\right)\right) \\
-\left(K_{3} s_{2}+K_{4} \int_{0}^{t_{2}}\left|\mathrm{~s}_{2}+\rho_{2} s_{2}^{\alpha_{2} / \beta_{2}}\right| d t \cdot \operatorname{Sign}\left(\mathrm{s}_{2}\right)\right)
\end{array}\right.
$$

Based on the control law, this paper takes $s_{1}$ as an example: control system trends to sliding mode in exponential trend when state variations are moving outside the sliding mode surface, while $\left|K_{1} s_{1}\right|$ becomes higher, the movement becomes faster and control system comes into the switching zone with the feature that movement speed crossing sliding mode surface is proportional to the absolute value of $K_{2} \int_{0}^{t_{1}}\left|\mathrm{~s}_{1}+\rho_{1} s_{1}^{\alpha_{1} / \beta_{1}}\right| d t \cdot \operatorname{Sign}\left(\mathrm{s}_{1}\right)$ when state variations are approaching the sliding mode surface, at last amplitude will become smaller so that to be stabilized to the origin with 0 error, which leads to the disappearance of sliding mode surface. In the expression $\int_{0}^{t_{2}}\left|\mathrm{~s}_{1}+\rho_{1} s_{1}^{\alpha_{1} / \beta_{1}}\right| d t$, when $\mathrm{s}_{1}>0$, $\rho_{1} s_{1}^{\alpha_{1} / \beta_{1}}<0$; when $\mathrm{s}_{1}<0, \rho_{1} s_{1}^{\alpha_{1} / \beta_{1}}>0$, they are opposite symbols, which avoids the increase in gain when the system is not on the sliding mode stage and weakens the chattering phenomenon.

\subsection{Demonstration of Robustness}

Switching function would be affected by parameter perturbation, external disturbances, measurement error and measurement noise, introduce the new interference $H$, we get:

$\dot{S}=F+D U+H$

Where $H=\left[\begin{array}{ll}H_{1} & H_{2}\end{array}\right]^{T}$ is the sum of interference, substitute (19) into (15) with control law (16), we get:

$$
\begin{aligned}
& \dot{V}=-s_{1}\left(K_{1} s_{1}-H_{1}+K_{2} \int_{0}^{t_{1}}\left|\mathrm{~s}_{1}+\rho_{1} s_{1}^{\alpha_{1} / \beta_{1}}\right| d t \cdot \operatorname{Sign}\left(\mathrm{s}_{1}\right)\right) \\
& -s_{2}\left(K_{3} s_{2}-H_{2}+K_{4} \int_{0}^{t_{2}}\left|\mathrm{~s}_{2}+\rho_{2} s_{2}^{\alpha_{2} / \beta_{2}}\right| d t \cdot \operatorname{Sign}\left(\mathrm{s}_{2}\right)\right)<0
\end{aligned}
$$

From formula(20),we will get $\dot{V}<0$ while $K_{2}>\left|H_{1}\right|$ and $K_{4}>\left|H_{2}\right|$. This shows permanent magnet synchronous motor vector control system has a better robustness against parameter perturbation, external disturbances, measurement error and measurement noise.

\subsection{Improvement of Chattering Phenomenon}

Variable structure control exists high frequency chattering phenomenon. Substituting continue function for switching function can reduce system disturbance effectively, continue function is as follows:

$\operatorname{sign}\left(\mathrm{s}_{i}\right)=\frac{s_{i}}{\left|s_{i}\right|+\sigma}$

Where $i=1,2, \quad \sigma$ is a small positive constant, we will adjust $\sigma$ appropriately to weaken the chattering phenomenon and improve the control precision.

\section{SIMULATION ANALYSIS}

Applied to a vector control system of PMSM as an example, we use Matlab do the design of current control system simulation. Motor parameters: rated torque $T_{N}=2 \mathrm{~N} . \mathrm{m}$ quadrature and direct axis inductance $L=15.5 \mathrm{mH}$, stator resistance $r=0.56 \Omega$, permanent magnetic flux $\psi_{f}=0.5072 \mathrm{~Wb}$, moment of inertia $J=0.0021 \mathrm{~kg} \cdot \mathrm{m}^{2}$,

poles $P=3$, viscous friction coefficient $B=0$. viscous friction coefficient $B=0$. Fig. (1) is the block diagram of the proposed control system.

Fig. (2) is speed response curve, where rated speed is $1000 \mathrm{r} / \mathrm{min}$, (a) speed responses with weighted integral gain sliding mode, (b) speed responses with conventional exponential reaching law sliding mode. Fig. (3) is torque response curve, where rated load torque is $2 N . m$ and jumps to $3 N . m$ at $0.1 \mathrm{~s}$, keeps another $0.1 \mathrm{~s}$ back to $2 N . m$, (a) torque responses with weighted integral gain sliding mode, (b) torque responses with conventional exponential reaching law sliding mode. From Fig. (2), we can see that speed based on conventional exponential reaching law sliding mode variable structure control produces great chattering at $0.1 \mathrm{~s} 、 0.2 \mathrm{~s}$ while speed based on weighted integral gain sliding mode control still can track the rated speed. Based on Figs. $(\mathbf{2}, \mathbf{3})$, we can see that weighted integral gain sliding mode variable structure control improves system's dynamic response and control precision.

Fig. (4) and Fig. (5) are motor stator three-phase current and stator current in $d-q$ axis. From Fig. (5), we can see that the stator current in d-axis almost keeps zero, tracking the rated stator current $i_{d}{ }^{*}=0$, and the stator current in q-axis relatively keeps smooth with small chattering, which confirms that weighted integral gain sliding mode variable structure control can weaken the chattering phenomenon effectively. 


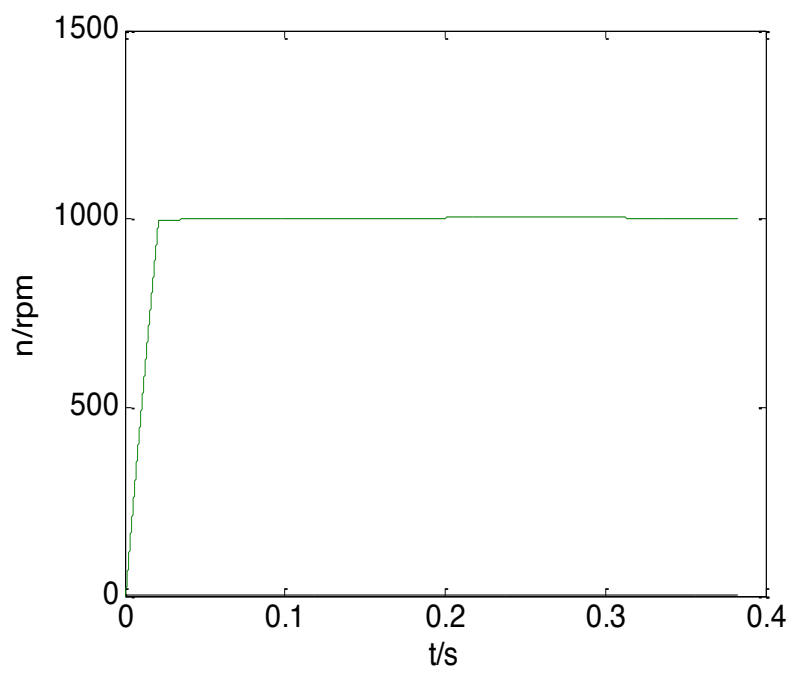

(a)

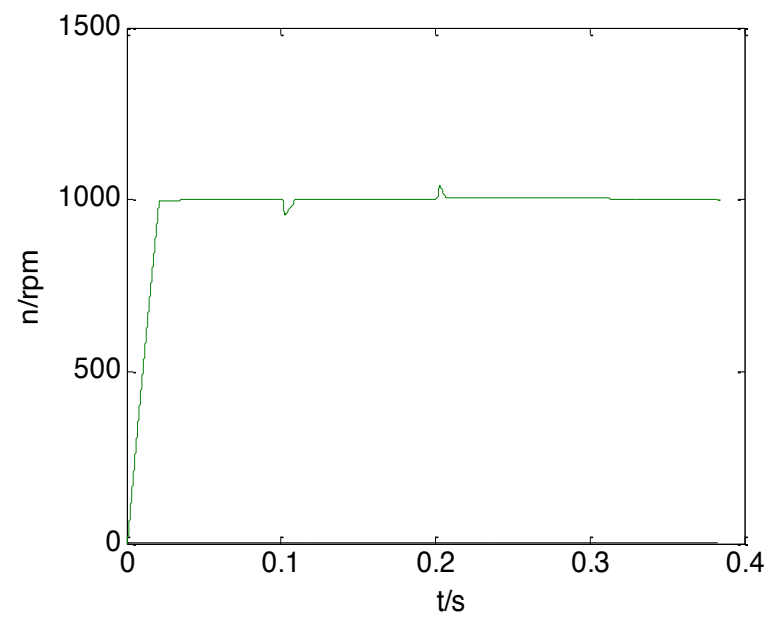

(b)

Fig. (2). Speed response curve.

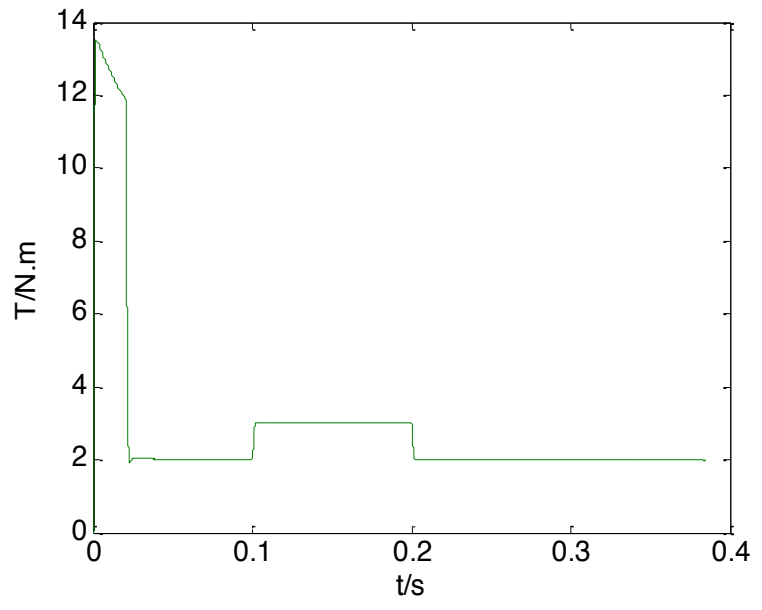

(a)

Fig. (3). Contd... 


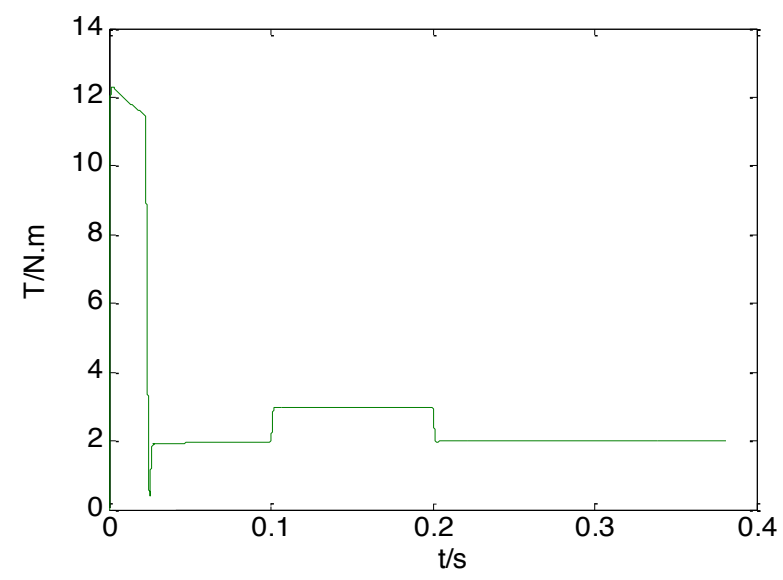

(b)

Fig. (3). Torque response curve.

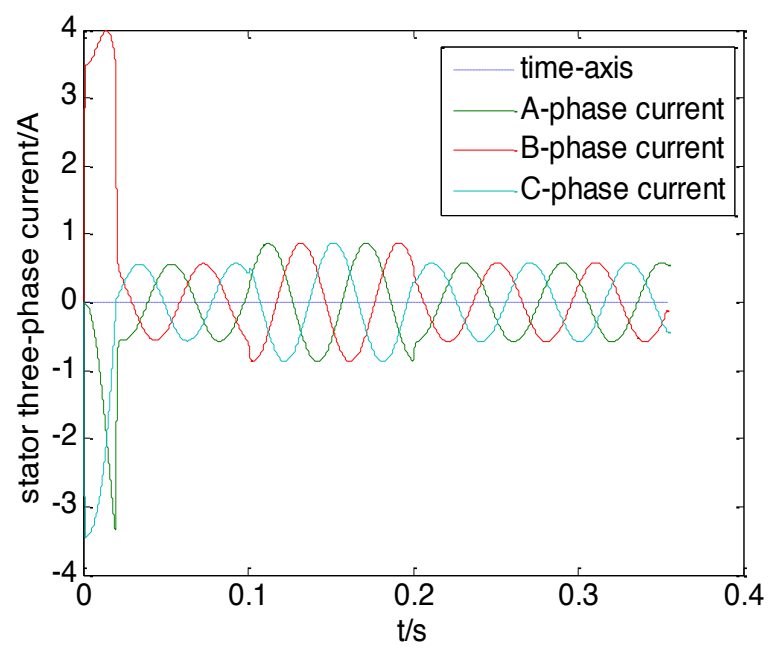

Fig. (4). Stator three-phase current.

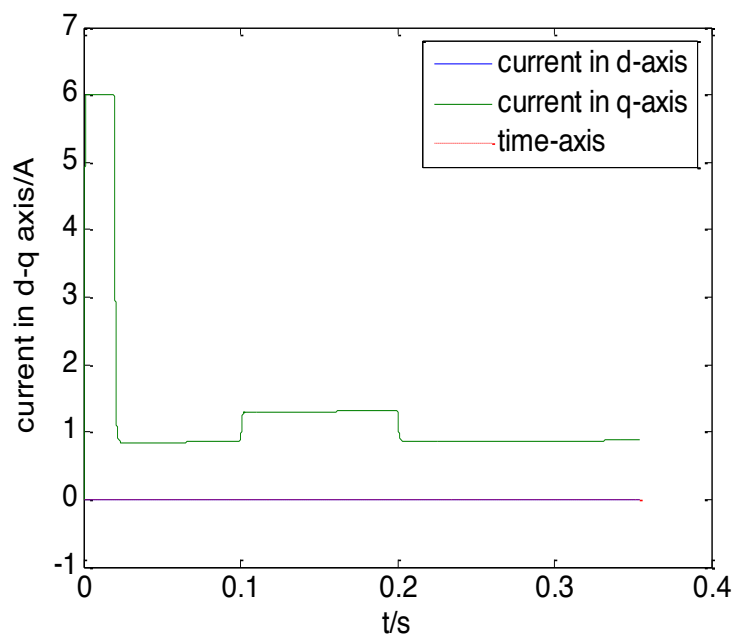

Fig. (5). Current of $d-q$ axis. 


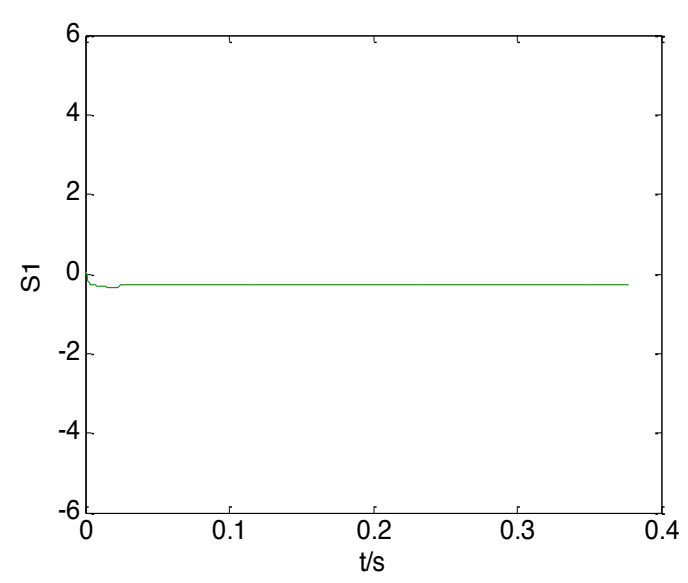

Fig. (6). Switching Function $s_{1}$.

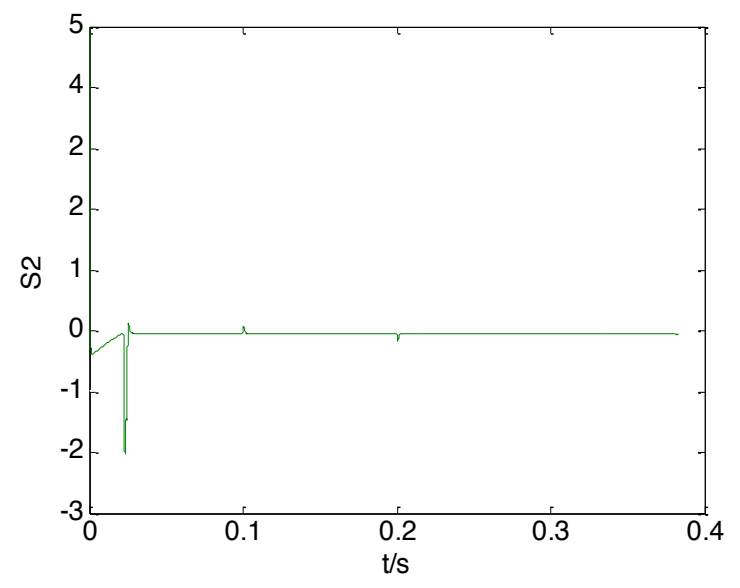

Fig. (7). Switching Function $S_{2}$.

Fig. (6) and Fig. (7) are waveforms of switching function $s_{1}$ and switching function $s_{2}$, they tend to zero in $0.05 \mathrm{~s}$, which indicates that $i_{d}$ and $i_{q}$ track the rated current in $d-q$ axis $i_{d}^{*} 、 i_{q}^{*}$.

\section{CONCLUSION}

Based on $i_{d}=0$ control strategy and multi variable, strong coupling and non autonomous system, this paper proposes a weighted integral type sliding mode variable structure control for permanent magnet synchronous motor's current control system. The theoretical analysis and the simulation structure show that, the proposed control strategy has a better robustness against load disturbances, a fast response speed, high precise speed tracking control, which are very suitable for frequency speed control system.

\section{CONFLICT OF INTEREST}

The authors confirm that this article content has no conflict of interest.

\section{ACKNOWLEDGEMENTS}

This work was financially supported by Open Fund Project of Jiangsu Provincial Key Lab of Pulp and Paper Science and Technology through the grant "201302", Graduate Research Practice Project of Jiangsu University of Science and Technology through the grant "YSJ14S-10", Zhenjiang Science and Technology Support Program (Social Development) Guidelines Project through the grant "FZ2013046", and A Project Funded by the Priority Academic Program Development of Jiangsu Higher Education Institution (PAPD).

\section{REFERENCES}

[1] Q. D. Guo, Y. B. Sun, and L. M. Wang, AC servo system of modern permanent magnet synchronous, Beijing: China power press, 2006.

[2] S. C. Fang, B. Zhou, and J. J. Huang, "Permanent magnet synchronous motor speed control system based on sliding mode", Journal of Electrician Technique, vol. 23, pp. 29-35, 2009.

[3] W. Zhang, and J. Q. Mao, "Adaptive fuzzy sliding-mode control method based on fuzzy tree mode", Control Theory and Applications, vol. 27, pp. 263-268, 2010.

[4] J. F. Zhen, Y. Fen, and Q. L. Lu, "High-order terminal sliding mode control of permanent magnet synchronous motor", Control Theory and Applications, vol. 26, pp. 97-700, 2009. 
[5] X. G. Zhang, K. Zhao, and S. Li, "Dynamic quality control of permanent magnet synchronous motor based on sliding mode variable structure", Chinese Journal of Electrical Engineering, vol. 31, pp. 47-52, 2011 .

[6] K. W. Dong, X. Zhang, and Y. Zhang, "Permanent magnet synchronous motor model of sliding mode variable structure control based on reaching law", Chinese Journal of Electrical Engineering, vol. 42, pp. 102-106, 2008.

[7] H. P. Jia, and Y. K. He, "Permanent magnet synchronous point sliding mode variable structure direction torque control", Journal of Electrician Technique, vol. 21, pp. 1-2, 2006.

[8] Y. Luo, and Y. Q. Chen, "Fractional order proportional derivative controller for a class of fractional order system", Automatica, vol. 45, pp. 2446-2450, 2009.

[9] H. Zhao, J. Y. Ma, S. J. Liu, and Y. J. Yue, "Fuzzy Sliding mode variable structure control of chaotic power system with uncertainty", Journal of Computational Information Systems, vol. 7, pp. 1959-1966, 2011.
[10] C. Lai, and S. Y. Ke, "A novel motor driver design for incremental motion system via sliding mode control method", IEEE Transactions on Industrial Electronics, vol. 52, pp. 599-507, 2005.

[11] J. Y. Cao, and B. B. Cao, "Digital realization and characteristics of fractional order controllers", Control Theory and Applications, vol. 23, pp. 792-793, 2009.

[12] X. Y. Luo, Z. H. Zhu, and X. P. Guan, "Chattering reduction adaptive sliding-mode control for nonlinear time-delay system", Control and Decision, vol. 24, pp. 1429-1435, 2009.

[13] W. P. Guo, and D. T. Liu, "Sliding mode supervised fuzzy control for a Class of underactuated nonlinear system", Journal of Computational Information Systems, vol. 10, pp. 493-500, 2013.

[14] X. Y. Wang, and H. Koc, "Observer-based decentralized fuzzy neural sliding network structure adaptation", Fuzzy Sets and Systems, vol. 16, pp. 2066-2080, 2010.

[15] S. Lin, Y. Luo, and Y. Q. Chen, "A fractional order proportional and derivative motion controller: tuning rule and experiments", IEEE Transactions on Control System Technology, vol. 18, pp. 53$63,2010$.

Received: December 15, 2014

Revised: January 04, 2015

Accepted: February 25, 2015

(C) Yi et al.; Licensee Bentham Open.

This is an open access article licensed under the terms of the Creative Commons Attribution Non-Commercial License (http://creativecommons.org/licenses/by$\mathrm{nc} / 3.0 /$ ) which permits unrestricted, non-commercial use, distribution and reproduction in any medium, provided the work is properly cited. 